Article

\title{
Study on the Activation of Scheelite and Wolframite by Lead Nitrate
}

\author{
Gang Zhao, Shuai Wang * and Hong Zhong * \\ College of Chemistry and Chemical Engineering, Central South University, Changsha, Hunan 410083, \\ China; E-Mail: zgmichaeljordan@163.com \\ * Authors to whom correspondence should be addressed; E-Mails: wangshuai@csu.edu.cn (S.W.); \\ zhongh@csu.edu.cn (H.Z.); Tel./Fax: +86-731-8883-0654 (S.W. \& H.Z.).
}

Academic Editor: Kota Hanumantha Rao

Received: 5 March 2015 / Accepted: 13 April 2015 / Published: 16 April 2015

\begin{abstract}
The activation of scheelite and wolframite by lead nitrate with benzohydroxamic acid (BHA) as collector was investigated by means of micro flotation test, zeta potential measurement, X-ray photoelectron spectroscopy (XPS) analyses and density functional theory (DFT) calculation. The flotation results confirmed that the addition of lead nitrate can markedly enhance the recovery of scheelite and wolframite. In the zeta potential curves obvious positive shifts were observed with the presence of lead nitrate. Lead was detected on mineral surface in microscopic analysis and the survey XP spectra. Both the electrokinetic study and XPS analyses indicated that lead ion can be adsorbed onto mineral surface. In DFT calculation, the coordination model of BHA with metal hydroxyl ions $\left(\mathrm{Ca}(\mathrm{OH})^{+}, \mathrm{Mn}(\mathrm{OH})^{+}, \mathrm{Fe}(\mathrm{OH})^{+}\right.$and $\left.\mathrm{Pb}(\mathrm{OH})^{+}\right)$was simulated and their binding energy were also calculated. The calculated results revealed that the binding ability of BHA and $\mathrm{Pb}(\mathrm{OH})^{+}$is the strongest, indicating that BHA can preferentially coordinate with $\mathrm{Pb}$ ion compared with $\mathrm{Ca}, \mathrm{Mn}$ and $\mathrm{Fe}$ ions.
\end{abstract}

Keywords: flotation; scheelite; wolframite; activation; lead nitrate; DFT

\section{Introduction}

Scheelite and wolframite ores are the most widely occurring tungsten minerals and have become the major raw materials in the tungsten industry. Froth flotation is used extensively as the primary 
concentration step in the recovery of minerals, in which activating agents play an important role in selective separation of minerals from gangues. The introduction of activator is an effective option when satisfactory flotation recovery cannot be acquired by collectors only. Meanwhile metal ions are one species of activators, such as $\mathrm{Ca}^{2+}, \mathrm{Fe}^{3+}, \mathrm{Cu}^{2+}, \mathrm{Pb}^{2+}$, etc [1-3].

In the flotation of scheelite and wolframite benzohydroxamic acid (BHA) is widely used as collector. As well-known chelating collector, hydroxamic acids are effective ligands with metal ions. The chelating performance of hydroxamic acids with transition metals including $\mathrm{Fe}, \mathrm{Ni}, \mathrm{Cu}$ and $\mathrm{Zn}$ has been studied through theoretical and experimental methods [4-6]. Research of chelation between hydroxamic acids and $\mathrm{Pb}$ has also been reported [7]. When hydroxamic acids are employed in the flotation of scheelite and wolframite, lead nitrate is widely applied as the activating agent. Chen and Ye studied the activation of wolframite flotation by lead nitrate and found that obvious activation occurred when $\mathrm{pH}<9.5$. The authors also concluded that $\mathrm{Pb}^{2+}$ and $\mathrm{Pb}(\mathrm{OH})^{+}$were the main components which activated wolframite [8]. Zhong et al made a contrastive study on the activation by different metal ions in wolframite flotation. Their work showed that the floatability of wolframite was only enhanced prominently by lead compared with the other metal ions, where the preferable $\mathrm{pH}$ was 6-10 [9]. As widely considered, computational methods such as ab initio and density functional theory (DFT) are valuable tools for us to understand chemical reactivity systems, which is also adopted to investigate the structure property and chemical reactivity of benzohydroxamic acid. Xia et al. studied the quantum chemical property of BHA using semi-empirical method PM3 (Parameterized Model Revision 3) and an ab initio method RHF (Restricted Hartree-Fork), and revealed that BHA existed mainly as keto-form and the five-member ring complex was formed through the two oxygen atoms of BHA with calcium atoms in scheelite surface [10]. Zhao et al. studied the performance of cyclohexyl hydroxamic acid compared with BHA in the flotation of scheelite through experimental methods (mineral flotation tests, adsorption measurement and zeta potential determination) in combination with DFT method. The conclusions drawn from DFT calculation were very in accord with the experimental results that cyclohexyl hydroxamic acid exhibited better collecting ability than BHA to scheelite [11]. Density functional theory has also been proved to be an accurate tool to explore the physical and chemical properties of scheelite-type and wolframite-type oxides [12,13].

In spite of a large number of studies conducted in the past, there are few reports about the DFT research for the coordination between hydroxamic acids and metal ions, much less for the activation of minerals, so the activation of scheelite and wolframite by lead nitrate is not yet well understood. The interaction between hydroxamic acids and relevant mineral ions $\left(\mathrm{Ca}^{2+}, \mathrm{Fe}^{2+}, \mathrm{Mn}^{2+}\right.$ and $\left.\mathrm{Pb}^{2+}\right)$ has crucial influences on the flotation of scheelite and wolframite. As a result, we may offer an explanation to the activation mechanism of lead nitrate in the flotation of scheelite and wolframite through the investigation of their coordination model. Our researches aim to provide a new insight or research method into the activation mechanism of lead nitrate in the flotation of scheelite and wolframite. We have examined the floatability of scheelite and wolframite by means of micro flotation, electrokinetic study and X-ray photoelectron spectroscopy (XPS) with quantum chemistry calculation as innovative approach to discuss the activation mechanism of lead nitrate experimentally and theoretically. 


\section{Materials and Experimental Section}

\subsection{Single Minerals}

Single minerals are provided by Guang Zhou Research Institute of Non-ferrous Metals (Guang Zhou, China). Chemical analysis and X-ray diffraction analysis are employed to analyze the compositions. The concentration of $\mathrm{WO}_{3}$ in scheelite is $79.8 \%$ and the mineral purity is $99 \%$. Main components in wolframite are $\mathrm{WO}_{3}(71.6 \%), \mathrm{Mn}(8.24 \%)$ and $\mathrm{Fe}(12.9 \%)$. The ores were ground to $0.037-0.076 \mathrm{~mm}$, washed by distilled water and then dried for flotation tests.

\subsection{Micro Flotation Tests}

The micro flotation tests of single mineral recovery were carried out as a function of $\mathrm{pH}$ and collector concentration using an XFG-type laboratory flotation cell of $40 \mathrm{~mL}$ capacity. In each test, $2.0 \mathrm{~g}$ sample was dispersed in the cell with distilled water for $1 \mathrm{~min}$. Then certain amount of lead nitrate solution was added and the pulp was activated for 2 min. The suspension $\mathrm{pH}$ was adjusted by $\mathrm{pH}$ regulator $(\mathrm{HCl}$ or $\mathrm{NaOH}$ aqueous solution) for $2 \mathrm{~min}$. Then collector was introduced and the mixture was agitated for $3 \mathrm{~min}$, followed by froth flotation for $5 \mathrm{~min}$. The floated and unfloated particles were collected, filtered and dried in a well-ventilated oven at $80{ }^{\circ} \mathrm{C}$ for $2 \mathrm{~h}$. The flotation recovery was calculated based on solid weight distributions between the two products.

\subsection{Zeta Potential Measurements}

The zeta potential was measured by analyzing $0.1 \mathrm{~g}$ of mineral in $100 \mathrm{~mL}$ of distilled water using Zeta Potential Analyzer (ZetaPALS, Brookhaven Instruments Corporation, New York, NY, USA). Before zeta potential measurements all samples were sonicated for $5 \mathrm{~min}$, followed by adjusting $\mathrm{pH}$ with $\mathrm{HNO}_{3}$ or $\mathrm{NaOH}$. The zeta potential was obtained from the electrophoretic mobility by the Smoluchowski equation. The reported zeta potential was averaged from five measurements.

\subsection{X-Ray Photoelectron Spectroscopy (XPS)}

XPS analyses were recorded on a Thermo Scientific ESCALAB 250Xi (Thermo Fisher Scientific, Waltham, MA, USA) using Al Ka X-ray source operated at $200 \mathrm{~W}$ with $20 \mathrm{eV}$ pass energy. The vacuum pressure was ranged from $10^{-9}$ to $10^{-8}$ Torr and the take off angle was $90^{\circ}$. The data were collected and processed under Thermo Scientific Avantage 4.52 software (Thermo Fisher Scientific). The integrated intensity of the observable peaks of all elements forming the surface layers is measured after the non-linear Shirley background subtraction. The carbon contamination peak at $285.0 \mathrm{eV}$ was used to account for charging a sample. XP spectra of C 1s, O 1s, Ca 2p, Mn 2p, Fe 2p, Pb 4f and W 4f electrons have been analyzed.

\section{Computational}

All the computations were performed by Chemoffice 2005 (CambridgeSoft, Cambridge, MA, USA) and Gaussian 03 (Gaussian, Wallingford, CT, USA). The initial molecular structures of benzohydroxamic acid (BHA) and metal ions were drawn by Chemoffice and optimized by MM2 
(a modified version of Allinger's MM2 force field) and PM3 (Parameterized Model Revision 3) methods. The molecular geometries obtained were further optimized by Gaussian with DFT methods (B3LYP) [14,15]. The energy and Mulliken charge population were calculated with the same basis set. To optimize the molecular structures in aqueous solution, IEF-PCM model (the integral equation formalism for the polarizable continuum model) was employed and the dielectric constant of water was 78.39. For light atoms ( $\mathrm{H}, \mathrm{C}, \mathrm{N}, \mathrm{O}, \mathrm{Ca}, \mathrm{Fe}$ and $\mathrm{Mn})$, the basis set $6-31+\mathrm{g}$ * was adopted, and the effective core potential (ECP) basis set LANL2DZ was used for heavy atom $(\mathrm{Pb})[16]$.

\section{Results and Discussion}

\subsection{Micro Flotation}

The micro flotation of pure minerals with BHA as collector was carried out with and without the addition of lead nitrate. Recoveries of scheelite and wolframite are showed in Figures 1 and 2.

Figure 1 shows the effect of slurry $\mathrm{pH}$ on the recoveries of scheelite and wolframite under the following conditions: the initial concentrations of $\mathrm{BHA}$ and $\mathrm{Pb}\left(\mathrm{NO}_{3}\right)_{2}$ are 150 and $45 \mathrm{mg} / \mathrm{L}$, respectively, and the temperature is $25^{\circ} \mathrm{C}$.

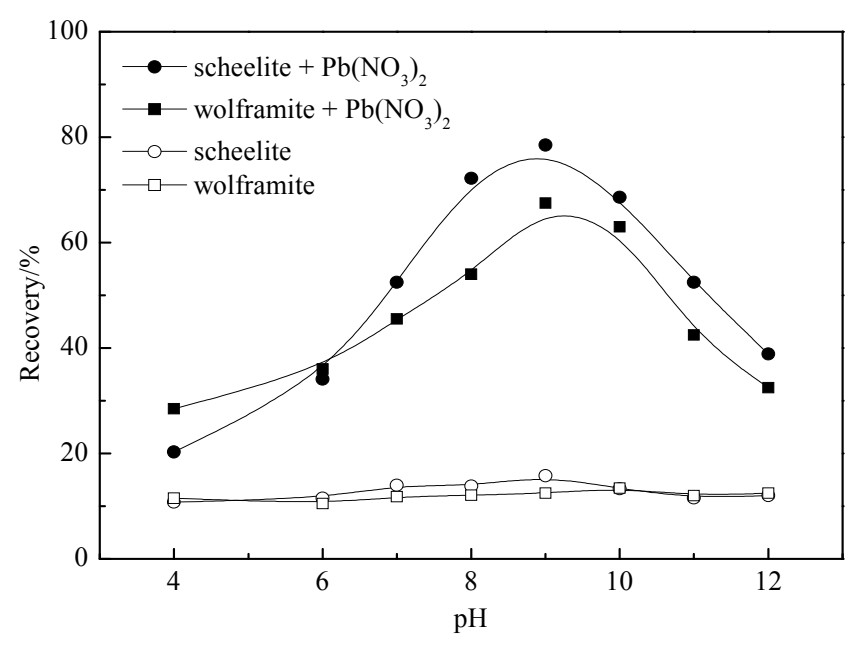

Figure 1. Recovery of scheelite and wolframite as a function of slurry $\mathrm{pH}$.

The figure indicates that the recoveries of scheelite and wolframite are very low without $\mathrm{Pb}\left(\mathrm{NO}_{3}\right)_{2}$, lower than $20 \%$ for both scheelite and wolframite during the experimental $\mathrm{pH}$ range. Meanwhile, at the presence of $\mathrm{Pb}\left(\mathrm{NO}_{3}\right)_{2}$, the collecting efficiencies of $\mathrm{BHA}$ increase a lot at the preferable flotation $\mathrm{pH}(8-10)$. At $\mathrm{pH} 9$, recoveries of scheelite and wolframite reach the highest values $(78.5 \%$ and $67.5 \%$, respectively). The effect of BHA dosages on the recoveries of scheelite and wolframite was examined at $\mathrm{pH}$ 9, as shown in Figure 2.

From Figure 2, the recoveries of scheelite and wolframite increase from $28.8 \%$ to $95.5 \%$ and $15.5 \%$ to $89.5 \%$ with the increase of BHA dosages from 50 to $300 \mathrm{mg} / \mathrm{L}$ in the presence of lead nitrate, respectively. But without the addition of $\mathrm{Pb}\left(\mathrm{NO}_{3}\right)_{2}$, their recoveries by $\mathrm{BHA}$ hardly increase, both lower than $20 \%$.

From the results above, scheelite and wolframite are apparently activated by lead nitrate. Effective activation may be accomplished due to the combination of BHA and lead adsorbed on mineral 
surfaces. Around $\mathrm{pH} 9$, the collector will ionize completely; meanwhile, lead on mineral surfaces is present as $\mathrm{Pb}^{2+}$ or $\mathrm{Pb}(\mathrm{OH})^{+}$. At lower $\mathrm{pH}$ the collector is mainly present as molecule or at higher $\mathrm{pH}$ lead changes to precipitation $\mathrm{Pb}(\mathrm{OH})_{2}$ resulting in difficult adsorption for collector. As a result, the activation could not be performed effectively at lower or higher $\mathrm{pH}$.

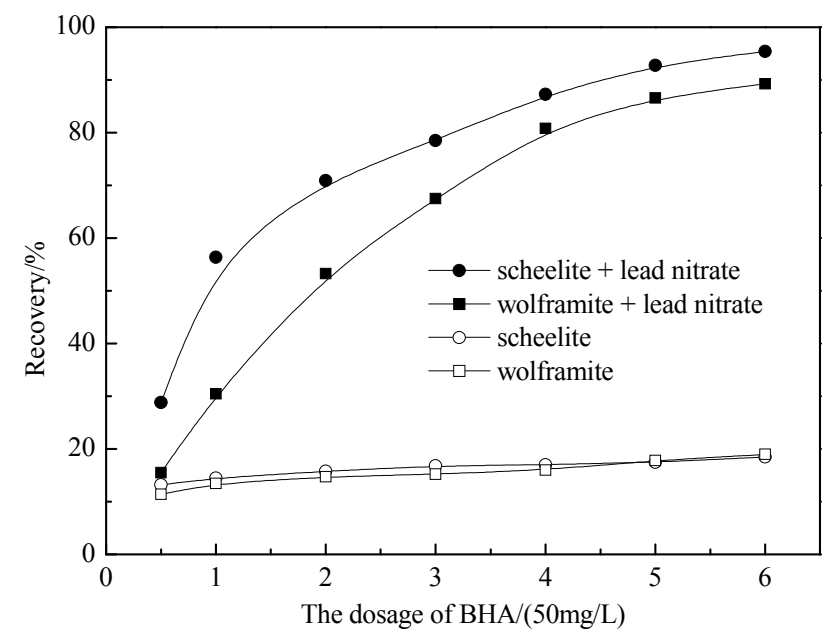

Figure 2. Recovery of scheelite and wolframite as a function of collector dosage.

\subsection{Electrokinetic Study}

Zeta potential is the electric potential in the interfacial double layer at the location of the slipping plane relative to a point in the bulk fluid away from the interface. It reflects the electrokinetic change on mineral surfaces in aqueous solution. The zeta potential of scheelite and wolframite in the presence and absence of lead nitrate were displayed in Figure 3. The primitive zeta potential of scheelite and wolframite are basically negative. The reason may be that metal ions in mineral surfaces preferentially dissolve into aqueous solution due to their stronger hydration ability than $\mathrm{WO}_{4}{ }^{2-}$, leaving more $\mathrm{WO}_{4}{ }^{2-}$ in mineral surface. After the addition of lead nitrate, positive shifts can be obviously observed for two minerals, which indicating the adsorption of $\mathrm{Pb}$ ions onto mineral surfaces. Meanwhile the zeta potential shift for scheelite is bigger compared with wolframite, and this may result in stronger enhancement of scheelite floatability after the addition of lead nitrate.

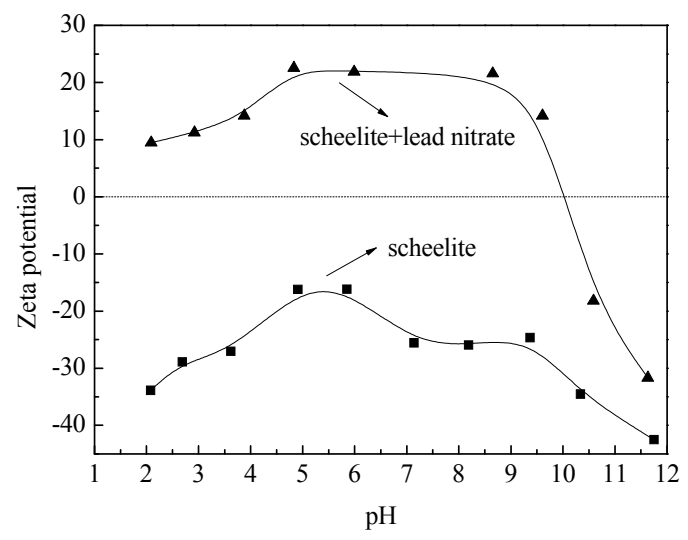

(a)

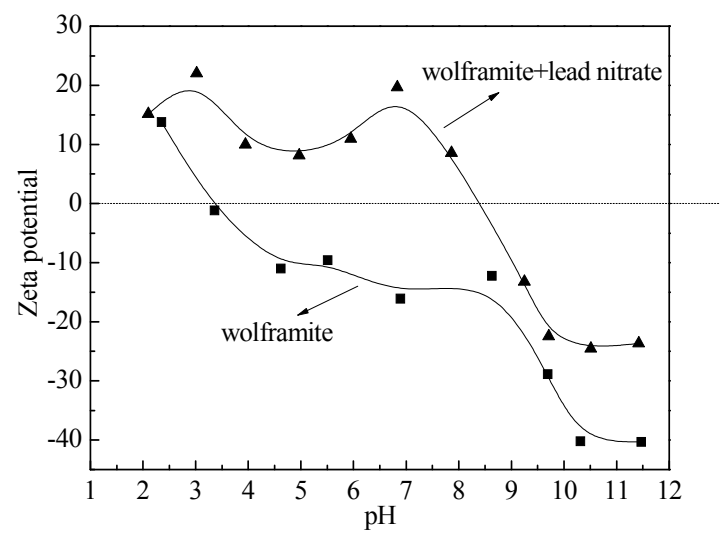

(b)

Figure 3. Zeta potential before and after the addition of lead nitrate: (a) scheelite; (b) wolframite. 


\subsection{XPS of Mineral Samples}

XPS is a surface chemical analysis technique that can be used to analyze the surface chemistry of a material. It is adopted to analyze the elemental composition of mineral surface and binding energy of elements on mineral surface. The surface elemental compositions were determined by microscopic analysis, as shown in Table 1.

Table1. Atom percentages for various samples as determined by X-ray photoelectron spectroscopy (XPS).

\begin{tabular}{cccccccc}
\hline Sample & $\mathbf{O}$ & $\mathbf{W}$ & $\mathbf{C a}$ & $\mathbf{P b}$ & Total & - & - \\
\hline scheelite & $67.58 \%$ & $15.62 \%$ & $16.81 \%$ & - & $100 \%$ & - & - \\
scheelite + lead nitrate & $68.16 \%$ & $15.05 \%$ & $14.98 \%$ & $1.81 \%$ & $100 \%$ & - & - \\
\hline Sample & $\mathbf{O}$ & $\mathbf{W}$ & $\mathbf{C a}$ & $\mathbf{M n}$ & $\mathbf{F e}$ & $\mathbf{P b}$ & Total \\
\hline wolframite & $68.65 \%$ & $12.96 \%$ & $1.79 \%$ & $12.36 \%$ & $4.22 \%$ & - & $100 \%$ \\
wolframite + lead nitrate & $68.61 \%$ & $11.52 \%$ & $1.29 \%$ & $11.27 \%$ & $4.44 \%$ & $2.86 \%$ & $100 \%$ \\
\hline
\end{tabular}

Table 1 showed that $\mathrm{Pb}$ occupied $1.81 \%$ and $2.86 \%$ on the chosen area of mineral surfaces after the addition of lead nitrate, respectively, which revealed that $\mathrm{Pb}$ was adsorbed onto mineral surfaces. The results were in accord with information from Figures 4 and 5, in which the survey XP spectra of atom orbitals were depicted. In the spectra of scheelite/wolframite with $\mathrm{Pb}, \mathrm{Pb} 4 \mathrm{f}$ orbital was detected by XPS and it also confirmed that the adsorption of $\mathrm{Pb}$ on mineral surfaces actually occurred.

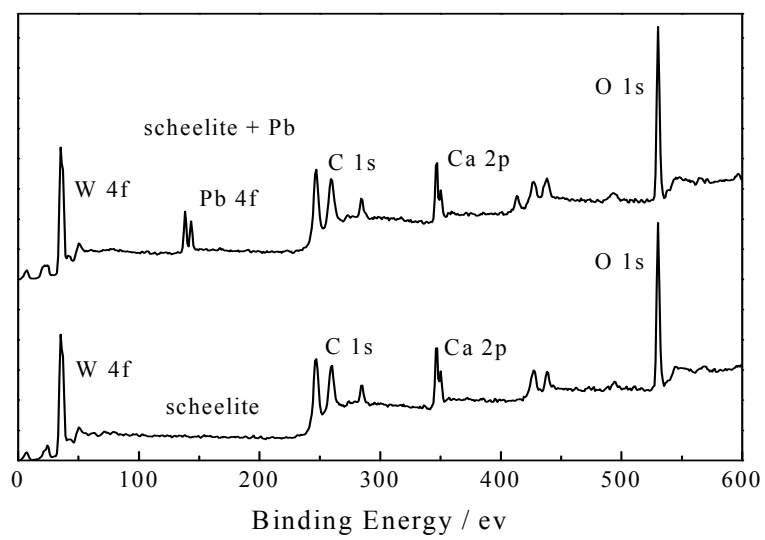

Figure 4. Spectra of atom orbitals for scheelite before and after lead adsorbed.

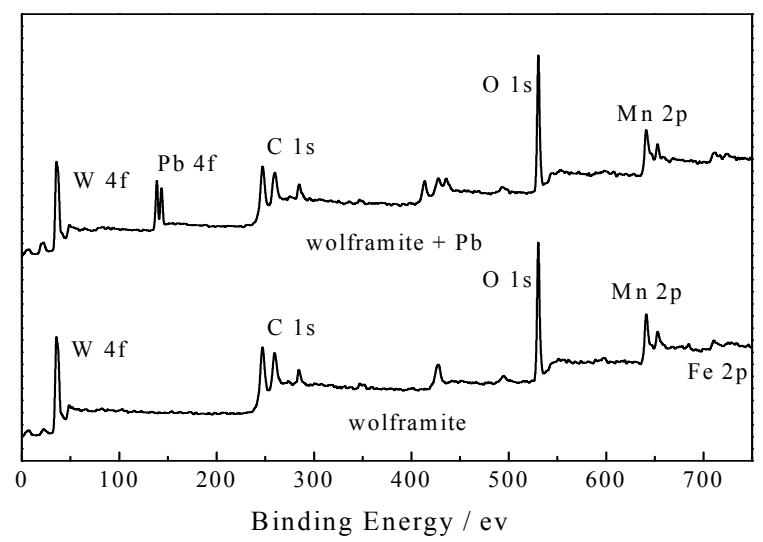

Figure 5. Spectra of atom orbitals for wolframite before and after lead adsorbed. 
Table 2 showed the binding energy of different atom orbits for scheelite and wolframite and that after the addition of lead nitrate. The results revealed that the binding energies of atom orbits on the surfaces of minerals changed after the addition of lead nitrate which indicated that lead ions were chemically adsorbed onto minerals surfaces.

Table 2. Binding energy of atom orbits on mineral surfaces before and after adding lead nitrate.

\begin{tabular}{cccc}
\hline \multirow{2}{*}{ Samples } & \multirow{2}{*}{ Atom Orbits } & \multicolumn{2}{c}{ Binding Energy } \\
\cline { 3 - 4 } Scheelite & Before Adsorption & After Adsorption \\
\hline \multirow{5}{*}{ Wolframite } & Ca 2p & 346.89 & 346.89 \\
& O 1s & 530.29 & 530.39 \\
& W 4f & 35.19 & 35.29 \\
\hline & Mn 2p & 640.59 & 640.49 \\
& Fe 2p & 710.79 & 710.89 \\
& O 2p & 530.49 & 530.39 \\
\hline
\end{tabular}

\subsection{Computational Results}

\subsubsection{Structure Properties of Benzohydroxamic Acid}

As generally known, there are two tautomers of hydroxamic acids: keto form and oxime form, as shown in Figure 6. The optimized structures of two forms for BHA were shown in Figure 7, and the corresponding energy values were calculated, as listed in Table 3.

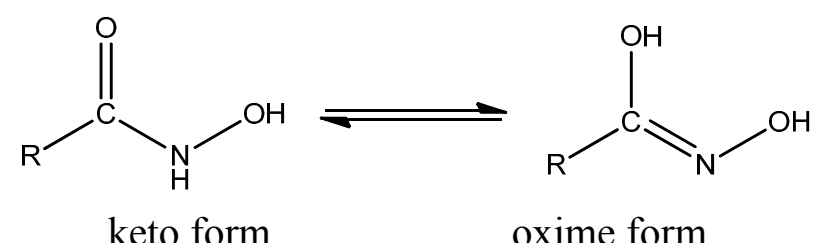

Figure 6. Two tautomers of hydroxamic acids.

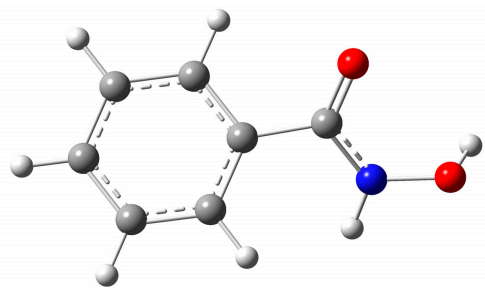

keto form

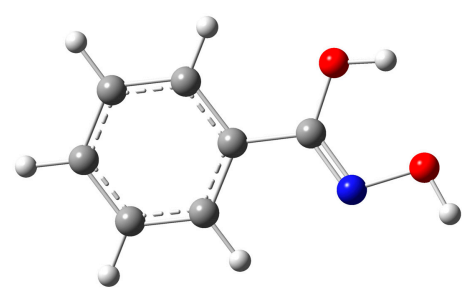

oxime form

Figure 7. Optimized molecular geometries of oxime form and keto form for benzohydroxamic acid (BHA).

Table 3. The calculated total energy of BHA in different forms.

\begin{tabular}{ccc}
\hline Tautomer & Molecule & Anion \\
\hline keto form & -476.262 & -475.786 \\
oxime form & -476.256 & -475.778 \\
\hline
\end{tabular}


From Table 3, the total energy of keto form is lower than oxime form for both molecular and ionic forms, which indicates that keto tautomer is more stable. Accordingly only this tautomer is considered in further study.

\subsubsection{Binding Model of BHA with Metal Ions}

For scheelite and wolframite, $\mathrm{Ca}, \mathrm{Mn}$ or Fe ions partially ionize into aqueous solution and the left metal ions are anchored on the mineral surface, which have vacant d-orbitals to accept electrons from collectors to form coordination bond. As a result, research of the coordination of BHA with $\mathrm{Ca}, \mathrm{Mn} / \mathrm{Fe}$ and $\mathrm{Pb}$ ions can help to investigate its collecting ability to scheelite and wolframite and the activation mechanism of lead nitrate. It has been reported that hydroxamic acid can chelate with metal ions to form five-member ring complexes [17,18], as shown in Figure 8a. In our previous work, we also adopted this combination model [11]. Here a more appropriate model was developed through further research by solution chemistry that $\mathrm{Pb}^{2+}$ mainly exists as $\mathrm{Pb}(\mathrm{OH})^{+}$form in aqueous solution at $\mathrm{pH} 8-10$, which is the preferable flotation $\mathrm{pH}$ for scheelite and wolframite [19]. The new binding model is shown in Figure 8b.

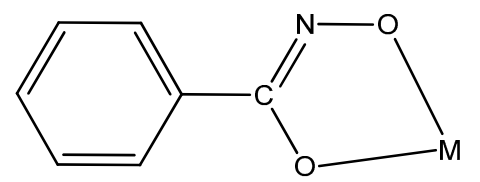

(a)

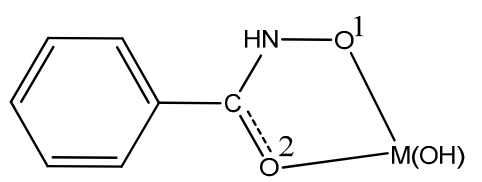

(b)

Figure 8. Binding models of BHA with metal ion (a) and metal hydroxyl ion (b).

The optimized geometries of the coordination compounds of BHA anion with $\mathrm{Ca}(\mathrm{OH})^{+}, \mathrm{Mn}(\mathrm{OH})^{+}$, $\mathrm{Fe}(\mathrm{OH})^{+}$and $\mathrm{Pb}(\mathrm{OH})^{+}$are shown in Figure 9.

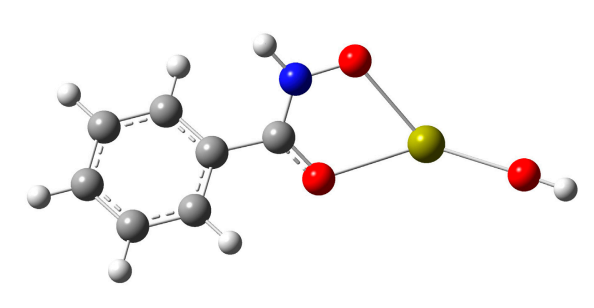

BHA- $\mathrm{Ca}(\mathrm{OH})$

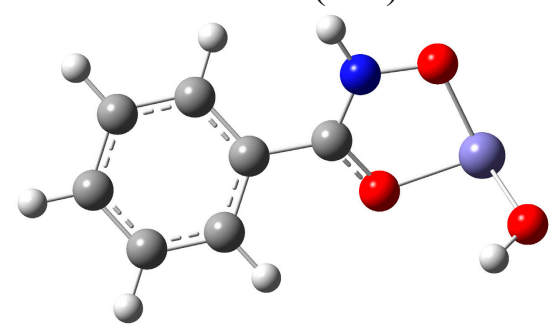

BHA-Fe(OH)

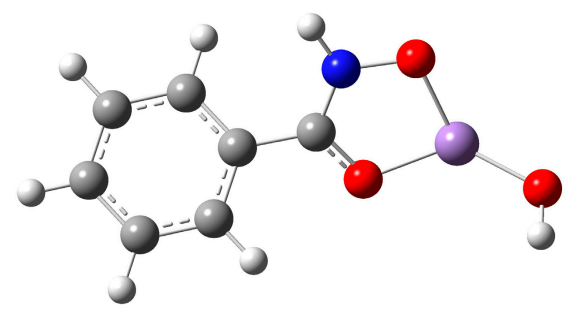

BHA-Mn(OH)

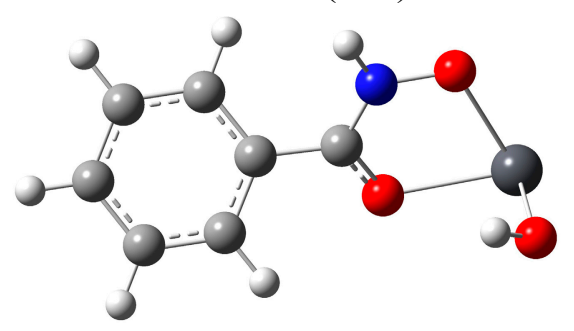

BHA-Pb(OH)

Figure 9. The optimized geometries of the coordination compounds of BHA anion with $\mathrm{Ca}(\mathrm{OH})^{+}, \mathrm{Mn}(\mathrm{OH})^{+}, \mathrm{Fe}(\mathrm{OH})^{+}$and $\mathrm{Pb}(\mathrm{OH})^{+}$. 


\subsubsection{Mulliken Charge and Binding Energy}

Binding ability of BHA with metal ions is represented by the transfer of Mulliken charge and calculated binding energy. Mulliken charge was first put forward by Robert Sanderson Mulliken to provide a means of estimating partial atomic charges from calculations carried out by the methods of computational chemistry, particularly those based on the linear combination of atomic orbitals molecular orbital method, and are routinely used as variables in linear regression procedures [20,21]. Here Mulliken charge was adopted to describe the net atomic charges of atoms participating in the coordination. The net charges of $\mathrm{O}$ atoms in hydroxamic group and metal ions before and after coordination are shown in Table 4.

Table 4. Mulliken charges of $\mathrm{O}$ atoms and metal ions.

\begin{tabular}{cccc}
\hline Species & $\mathbf{O}^{\mathbf{1}}$ & $\mathbf{O}^{\mathbf{2}}$ & Metal Ions \\
\hline BHA anion & -0.753 & -0.557 & - \\
BHA-Ca(OH) & -0.758 & -0.464 & 1.681 \\
BHA-Mn(OH) & -0.517 & -0.327 & 1.053 \\
BHA-Fe(OH) & -0.431 & -0.214 & 0.927 \\
BHA-Pb(OH) & -0.428 & -0.202 & 0.785 \\
\hline
\end{tabular}

From Table 4, the absolute values of Mulliken charges on $\mathrm{O}$ atoms become smaller after binding with metal ions. Correspondingly, the positive charges on metal ions get smaller too, which is +2 before combination. In another word, the electrons transferred from $\mathrm{O}$ atoms to metal ions obviously. Meanwhile, the greatest change occurred for the Mulliken charge of $\mathrm{Pb}$, from $(+2)$ to $(+0.785)$. Therefore the combination of BHA with $\mathrm{Pb}$ ion is the strongest.

The energy of hydroxyl metal ions, system energy of BHA-M(OH) $(\mathrm{M}=\mathrm{Ca}, \mathrm{Mn}, \mathrm{Fe}$ and $\mathrm{Pb})$ and the calculated binding energy were listed in Table 5, where the energy of BHA anion is -475.669 (a.u.).

Table 5. Calculated energies in binding models.

\begin{tabular}{ccccc}
\hline Species & BHA-Ca(OH) & BHA-Mn(OH) & BHA-Fe(OH) & BHA-Pb(OH) \\
\hline Hydroxyl metal ions Energy/a.u. & -753.396 & -1226.511 & -1339.220 & -79.176 \\
System Energy/a.u. & -1229.11 & -1702.22 & -1814.95 & -554.925 \\
Binding Energy/(kJ/mol) & -105.02 & -118.15 & -152.28 & -210.04 \\
\hline
\end{tabular}

The binding energy of BHA with metal ions is calculated according to the following equation: $E_{\mathrm{B}}=E_{\mathrm{S}}-\left(E_{\mathrm{M}}+E_{\mathrm{BHA}}\right)$, where $E_{\mathrm{B}}$ is the binding energy; $E_{\mathrm{S}}$ is the system energy of binding model; $E_{\mathrm{M}}$ and $E_{\mathrm{BHA}}$ are the energy of hydroxyl metal ions and BHA anion respectively. From the table, the values of binding energy are all negative, that is, BHA can coordinate with these metal ions spontaneously. However the coordination reactivity is in varying degrees. The absolute values of the binding energy conform to the following sequence: $\mathrm{Pb}>\mathrm{Fe}>\mathrm{Mn}>\mathrm{Ca}$. So the combination of BHA anion with $\mathrm{Pb}$ ion is preferential.

As a matter of fact, the computational results help to explain the activation mechanism of $\mathrm{Pb}^{2+}$ in the flotation of scheelite and wolframite in a certain degree. 


\section{Conclusions}

In this work, the flotation tests and electrokinetic study with XPS analyses and DFT calculation is an interesting combination employed to study the activation of scheelite and wolframite by lead nitrate. Following conclusions can be drawn from the results and discussion.

(1) Pure mineral flotation showed that the addition of $\mathrm{Pb}\left(\mathrm{NO}_{3}\right)_{2}$ had obvious enhancements on the recovery of scheelite and wolframite.

(2) The results of electrokinetic study and XPS analyses indicated that lead ion can be adsorbed onto mineral surfaces.

(3) On the basis of the calculated binding energy and Mulliken charge population, the binding ability of BHA with $\mathrm{Pb}$ is stronger compared with $\mathrm{Ca}, \mathrm{Mn}$ and $\mathrm{Fe}$.

(4) Effective activation is supposed to be achieved by adsorption of lead on mineral surfaces and coordination of collector with lead ions.

\section{Acknowledgments}

The authors would like to acknowledge the financial support from the National High Technology Research and Development Program of China (863 Program, No. 2013AA064102) and the Hunan Provincial Innovation Foundation for Postgraduate (No. CX2012B120). This project was also supported by High Performance Computing Center of Central South University, China. All the calculations were performed on this platform.

\section{Author Contributions}

S.W. and H.Z. conceived and designed the experiments; G.Z. performed the experiments and analyzed the data; S.W. and H.Z. contributed reagents/materials/analysis tools; G.Z. and S.W. wrote the paper.

\section{Conflicts of Interest}

The authors declare no conflict of interest.

\section{References}

1. Kirjavainen, V.; Schreithofer, N.; Heiskanen, K. Effect of calcium and thiosulfate ions on flotation selectivity of nickel-copper ores. Miner. Eng. 2002, 15, 1-5.

2. Finkelstein N.P. The activation of sulphide minerals for flotation: A review. Int. J. Miner. Process. 1997, 52, 81-120.

3. Fan, X.; Rowson, N.A. The effect of $\mathrm{Pb}\left(\mathrm{NO}_{3}\right)_{2}$ on ilmenite flotation. Miner. Eng. 2000, 13, 205-215.

4. Buglyó, P.; Eszter Márta Nagya, E.M.; Farkasa, E.; Sóvágóa, I.; Sannab, D.; Micera, G. New insights into the metal ion-peptide hydroxamate interactions: Metal complexes of primary hydroxamic acid derivatives of common dipeptides in aqueous solution. Polyhedron 2007, 26, 1625-1633. 
5. Griffith, D.M.; Szőcs, B.; Keogh, T.; Suponitsky, K.Y.; Farkas, E; Buglyó, P.; Marmion, C.J. Suberoylanilide hydroxamic acid, a potent histone deacetylase inhibitor; its X-ray crystal structure and solid state and solution studies of its $\mathrm{Zn}(\mathrm{II}), \mathrm{Ni}(\mathrm{II}), \mathrm{Cu}(\mathrm{II})$ and $\mathrm{Fe}(\mathrm{III})$ complexes. J. Inorg. Biochem. 2011, 105, 763-769.

6. Šille, J.; Šramko, M.; Garaj, V.; Remko, M. Gas phase and solution state stability of complexes L...M, where $\mathrm{M}=\mathrm{Cu}^{2+}, \mathrm{Ni}^{2+}$, or $\mathrm{Zn}^{2+}$ and $\mathrm{L}=\mathrm{R}-\mathrm{C}(\mathrm{O}) \mathrm{NHOH}\left(\mathrm{R}=\mathrm{H}, \mathrm{NH}_{2}, \mathrm{CH}_{3}, \mathrm{CF}_{3}\right.$, or Phenyl). J. Mol. Struct. Theochem 2009, 911, 137-143.

7. Ali, O.Y.; Fridgen, T.D. Structures of electrosprayed $\mathrm{Pb}(\text { Uracil-H })^{+}$complexes by infrared multiple photon dissociation spectroscopy. Int. J. Mass Spectrom. 2011, 308, 167-174.

8. Chen, W.X.; Ye, Z.P. Study on wolframite flotation activated by lead nitrate. J. Guangdong Non-ferr. Met. 1999, 9, 13-17.

9. Zhong, C.G.; Gao, Y.D.; Qiu, X.Y.; Feng, Q.M. The effects of metal ions on wolframite flotation with benzohydroxamic acid. China Tungsten Ind. 2013, 28, 22-25.

10. Xia, Q.B.; Li, Z.; Qiu, X.Y.; Dai, Z.L. Quantum chemical study on benzyhydroxamic acid flotation agent. Min. Metall. Eng. 2004, 24, 30-33.

11. Zhao, G.; Zhong, H.; Qiu, X.Y.; Wang, S.; Gao, Y.D.; Dai, Z.L.; Huang, J.P.; Liu, G.Y. The DFT study of cyclohexyl hydroxamic acid as a collector in scheelite flotation. Miner. Eng. 2013, 49, 54-60.

12. Perales, R.L.; Errandonea, D.; Segura, A.; Fuertes, J.R.; Hernandez, P.R.; Radescu, S.; Solano, J.L.; Mujica, A.; Munoz, A. A combined high-pressure experimental and theoretical study of the electronic band-structure of scheelite-type $\mathrm{AWO}_{4}(\mathrm{~A}=\mathrm{Ca}, \mathrm{Sr}, \mathrm{Ba}, \mathrm{Pb})$ compounds. J. Appl. Phys. 2011, 110, doi:10.1063/1.3622322.

13. Fuertes, J.R.; Moreno, S.L.; Solano, J.L.; Errandonea, D.; Segura, A.; Perales, R.L.; Munoz, A.; Radescu, S.; Hernandez, P.R.; Gospodinov, M.; et al. Pressure effects on the electronic and optical properties of $\mathrm{AWO}_{4}$ wolframites $(\mathrm{A}=\mathrm{Cd}, \mathrm{Mg}, \mathrm{Mn}$, and $\mathrm{Zn})$ : The distinctive behavior of multiferroic $\mathrm{MnWO}_{4}$. Phys. Rev. B 2012, 86, doi:10.1103/PhysRevB.86.125202.

14. Gece, G.; Bilgiç, S. A theoretical study of some hydroxamic acids as corrosion inhibitors for carbon steel. Corros. Sci. 2010, 52, 3304-3308.

15. Liu, G.Y.; Zeng, H.B.; Lu, Q.Y.; Zhong, H.; Choi, P.; Xu, Z.H. Adsorption of mercaptobenzoheterocyclic compounds on sulfide mineral surfaces: A density functional theory study of structure-reactivity relations. Colloids Surf. A 2012, 409, 1-9.

16. Schuchardt, K.L.; Didier, B.T.; Elsethagen, T.; Sun, L.; Gurumoorthi, V.; Chase, J.; Li, J.; Windus, T.L. Basis Set Exchange: A Community Database for Computational Sciences. J. Chem. Inf. Model. 2007, 47, 1045-1052.

17. Qiu, X.Y.; Cheng, D.M.; Wang, D.Z. Reaction mechanism between benzoylhydroxamic acid and scheelite. Min. Metall. Eng. 2001, 21, 39-42.

18. Etelka, F.; David, B.; Edit, C.; Peter, B.; Wolfgang, H.; Daniele, S. Synthesis and characterization of $\mathrm{Cu}^{2+}, \mathrm{Ni}^{2+}$ and $\mathrm{Zn}^{2+}$ binding capability of some amino- and imidazole hydroxamic acids: Effects of substitution of side chain amino-N for imidazole-N or hydroxamic- $\mathrm{N}-\mathrm{CH}_{3}$ on metal complexation. Polyhedron 2007, 26, 543-554.

19. Jin, H.A.; Li, B.D. Activation mechanism of metal cation in wolframite flotation. Nonferr. Met. 1980, 32, 46-55. 
20. Mulliken, R.S. Electronic Population Analysis on LCAO-MO Molecular Wave Functions. J. Chem. Phys. 1955, 23, 1833-1840.

21. Csizmadia, I.G. Theory and Practice of MO Calculations on Organic Molecules; Elsevier: Amsterdam, The Netherland, 1976.

(C) 2015 by the authors; licensee MDPI, Basel, Switzerland. This article is an open access article distributed under the terms and conditions of the Creative Commons Attribution license (http://creativecommons.org/licenses/by/4.0/). 